\title{
Original
}

\section{Characteristics and Alterations of Food Intake in Children with Pervasive Developmental Disorders -Behavioral Analysis of Spoon Feeding-}

\author{
Nakako OgawA, Shouji HiRonaKA and Yoshiharu MuKaI \\ Department of Hygiene and Oral Health, Showa University School of Dentistry \\ 1-5-8 Hatanodai, Shinagawa-ku, Tokyo, 142-8555 Japan \\ (Chief: Prof. Yoshiharu Mukai)
}

\begin{abstract}
Studies on feeding behaviors of children with pervasive developmental disorders (PDD) have focused mainly on problematic behaviors such as food selectivity and how to deal with them. Few studies have addressed the motor aspects of feeding behavior. This study aimed to determine the characteristics of feeding behavior of children with PDD using a spoon. The study participants consisted of 8 children with PDD attending a childrens disability center (6 boys and 2 girls; mean $\pm \mathrm{SD}=36.1 \pm 4.2$ months). Feeding behaviors of the participants at lunch time were videotaped. They were also assessed with the Enjoji Scale of Infant Analytical Development Test on the same day. These 2 assessment procedures were repeated about one year later. The control group consisted of 5 healthy children ( 2 boys and 3 girls; mean $\pm \mathrm{SD}=43.2 \pm 7.4$ months). The following results were obtained. Comparison between the children with PDD and controls showed significant differences in "motion of lips during food intake" and "neck rotation". Correlations between the feeding assessment and the Enjoji Scale were as follows. On the first assessment, "motion of the lips during food intake" did not correlate significantly with any items of the Enjoji Scale. However, on the second assessment, this item showed significant correlations with all Enjoji Scale items. The characteristics of children with PDD were considered to lesser motion of the lips and neck rotation. We speculate that development of lip motions might be greatly influenced by therapeutic education.
\end{abstract}

Key words: feeding function, spoon feeding, lip motions during food intake, The Enjoji Scale of Infant Analytical Development Test, Pervasive Developmental Disorders.

Feeding function can be investigated or treated based on a 5 -stage process of ingestion: pre-oral (anticipatory), preparatory, lingual, pharyngeal, and esophageal. ${ }^{1)}$ Oral intake of food starts in the preparatory stage, and this process is considered to have a large effect on subsequent processes. ${ }^{2,3)}$

In healthy infants, feeding function develops along with the change of food material. After birth, feeding behavior is mostly restricted to sucking milk. In the weaning period, infants start to acquire solid food intake functions. The oral function for solid food intake consists of swallowing, capturing, and mastication. ${ }^{4)}$ In the later weaning period, infants gradually become independent in eating by starting to feed themselves with the fingers. ${ }^{5)}$
This "finger feeding" leads to motor coordination development of the jaw, lips, arms, and fingers. After this process, they begin "spoon feeding."

For the purpose of identifying and treating problems as early as possible, a number of assessment methods for feeding function of infants have been reported; however, most oral assessments are restricted to mastication function. In these assessments, the lips are assumed mainly to serve a sealing function during mastication. An assessment method for evaluating hand-mouth coordination during spoon feeding in healthy infants was developed. ${ }^{6)}$ This assessment method, designed to evaluate hand-mouth coordination and lip motions during food intake, was subsequently applied to a study of hand-

(Received October 26, 2011; Accepted for publication January 20, 2012) 
mouth coordination during food intake in intellectually handicapped children. ${ }^{\text {) }}$

According to the Diagnostic and Statistical Manual for Mental Disorders IV TR ${ }^{8}{ }^{8}$ PDD consists of Asperger's disorder, Childhood autism, PDD not otherwise specified, Rett's disorder and Childhood disintegrative disorders.

The diagnostic criteria for autistic disorder include qualitative impairment in social interaction, qualitative impairment in communication, restricted repetitive and stereotyped patterns of behavior, interests and activities. A significant research effort was made to investigate the underlying causes of these conditions, and developmental impairment in the central nervous system has been considered to play an important role. ${ }^{9)}$ While communication is an important aspect of diagnostic evaluation of children with autistic disorder, the presence of sensory and motor impairments also has been indicated. ${ }^{10,11)}$ Children with PDD display a variety of feeding-related behavior problems. Food selectivity and pica are frequently observed. ${ }^{12)}$ In addition, other problematic behaviors such as eating while walking around, throwing food, and shoveling food into the mouth have been reported. ${ }^{13)}$ These feeding-related behavior problems emerge in infancy and disturb parents. ${ }^{14)}$ Therapeutic approaches for these problematic behaviors have also been reported. ${ }^{15)}$ On the other hand, the number of studies focusing on motor aspects of feeding function is small. Although there is a report indicating lesser mastication, ${ }^{16}$ the underlying cause has not been clarified. Given that feeding function is a motor act triggered by sensory input, sensory and motor aspects of feeding disorders in children with PDD warrant study. ${ }^{17)}$ Oral intake of food starts in the preparatory stage, and this process is considered to have a large effect on subsequent processes. This study aimed to determine the characteristics of lip motion and handmouth coordination during food intake in children with PDD, using the assessment criteria developed by Tamura et $\mathrm{al}^{(6)}$ and to identify factors related to the developmental changes.

\section{Methods}

\section{Participants and Procedures}

Study participants were selected from among children with PDD attending a children's disability center. Informed consent for study participation was obtained from the parents. Eligible 8 children ( 6 boys and 2 girls; age range, $31-42$ months, mean $\pm \mathrm{SD}=36.1 \pm 4.2$ months) capable of self-feeding were videotaped while eating at 2 time points with the intervals of about one year. Participants ate a dish of rice in their therapy room. None of therapists helped them.

This study was conducted between July 2008 and December 2009. To evaluate feeding behavior changes, participants were videotaped while eating. In addition, The Enjoji Scale of Infant Analytical Development Test ${ }^{18)}$ (Table 1) was implemented on the same day because this scale test was derived from a large scale survey conducted in 1977 on 1,718 infants (854 boys and 864 girls) and has been widely used in Japan.

The videotaping was performed by the first author, and the assessment was done by all authors. We had more than fifteen years' experiences for conducting the assessment. The assessment criteria for food intake behavior are shown in Table 2. These items were revisions of the criteria developed by Tamura et $\mathrm{al}^{(6)}$ and Nomoto et al. ${ }^{7)}$ Examples of the assessment are shown in Fig. 1.

The control group consisted of 5 typically developing children with neither body structure nor function abnormalities ( 2 boys and 3 girls; age range, 32-52 months, mean $\pm \mathrm{SD}=43.2 \pm 7.4$ months). Their feeding behaviors were videotaped under the same conditions as those for the PPD children.

In the feeding assessment, the participant ate white rice using a spoon and dish which they had been using at the disability center. No one highly preferred white rice or disliked it. All of them moderately preferred.

Scores for each of the assessment items were compared between two datasets, i.e., the first vs. the second assessment for the PDD children; the first assessment 
Table 1 The Enjoji Scale of Infant Analytical Development Test (part).

\begin{tabular}{|c|c|c|c|c|c|c|}
\hline \multirow{2}{*}{$\begin{array}{c}\text { Age } \\
\text { (months) }\end{array}$} & \multicolumn{2}{|c|}{ Exercise } & \multicolumn{2}{|c|}{ Sociality } & \multicolumn{2}{|c|}{ Language } \\
\hline & $\begin{array}{l}\text { Physical } \\
\text { movement }\end{array}$ & Hand movement & Basic daily habits & Personal relations & Speaking & $\begin{array}{l}\text { Understanding of } \\
\text { language }\end{array}$ \\
\hline 46 & $\begin{array}{l}\text { Child can hop } \\
\text { with one foot for } \\
\text { a few times. }\end{array}$ & $\begin{array}{l}\text { Cut a sheet of } \\
\text { paper along a } \\
\text { straight line. }\end{array}$ & $\begin{array}{l}\text { Child can wash his } \\
\text { body by himself to } \\
\text { some extent. }\end{array}$ & $\begin{array}{l}\text { Go to a friend's } \\
\text { house to play } \\
\text { giving a mother } \\
\text { notice beforehand. }\end{array}$ & $\begin{array}{c}\text { Give the parents' } \\
\text { names and } \\
\text { address. }\end{array}$ & $\begin{array}{c}\text { Give instructions } \\
\text { of objects by their } \\
\text { usage. }\end{array}$ \\
\hline 42 & $\begin{array}{l}\text { Child can jump } \\
\text { forward } \\
\text { with both feet. }\end{array}$ & $\begin{array}{c}\text { Child can } \\
\text { write a cross. }\end{array}$ & $\begin{array}{l}\text { Child can blow } \\
\text { his nose. }\end{array}$ & $\begin{array}{l}\text { Use things by } \\
\text { turns with friends. }\end{array}$ & $\begin{array}{l}\text { Repeat a sentence. } \\
\text { e.g. A pretty flower } \\
\text { is in bloom. }\end{array}$ & $\begin{array}{l}\text { Understand the } \\
\text { numerical } \\
\text { concept. }\end{array}$ \\
\hline 38 & $\begin{array}{l}\text { Child can tumble } \\
\text { by himself. }\end{array}$ & $\begin{array}{l}\text { Child can } \\
\text { fasten buttons } \\
\text { by himself. }\end{array}$ & $\begin{array}{l}\text { Child can wash } \\
\text { his face by } \\
\text { himself. }\end{array}$ & $\begin{array}{l}\text { Ask permission } \\
\text { such as : Can I do } \\
\text { this?' }\end{array}$ & $\begin{array}{c}\text { Have a } \\
\text { conversation with } \\
\text { the children of the } \\
\text { same age. }\end{array}$ & $\begin{array}{l}\text { Understand the } \\
\text { difference between } \\
\text { high and low. }\end{array}$ \\
\hline 35 & $\begin{array}{l}\text { Stand still for a } \\
\text { few seconds on } \\
\text { one foot. }\end{array}$ & $\begin{array}{l}\text { Child can cut a } \\
\text { piece of paper } \\
\text { with scissors. }\end{array}$ & $\begin{array}{l}\text { Child can take off } \\
\text { a coat by himself. }\end{array}$ & $\begin{array}{l}\text { To be able to } \\
\text { play house. }\end{array}$ & $\begin{array}{c}\text { Repeat two } \\
\text { combined words. }\end{array}$ & $\begin{array}{l}\text { Understand the } \\
\text { difference between } \\
\text { red, blue, yellow, } \\
\text { and green. }\end{array}$ \\
\hline 32 & $\begin{array}{l}\text { Turn around while } \\
\text { standing }\end{array}$ & $\begin{array}{l}\text { Child can write a } \\
\text { circle following } \\
\text { the example. }\end{array}$ & $\begin{array}{l}\text { Child can put on } \\
\text { his shoes by } \\
\text { himself. }\end{array}$ & $\begin{array}{l}\text { Try to look after } \\
\text { smaller children. }\end{array}$ & $\begin{array}{l}\text { Repeat two } \\
\text { combined } \\
\text { numbers. }\end{array}$ & $\begin{array}{c}\text { Understand the } \\
\text { difference between } \\
\text { long and short. }\end{array}$ \\
\hline
\end{tabular}

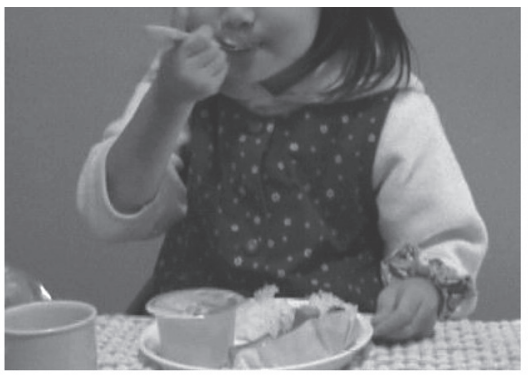

Typically developing child

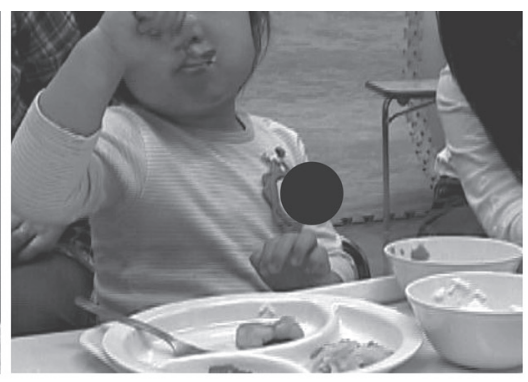

Child with PDD

\begin{tabular}{|c|l|c|}
\hline 3 & $\begin{array}{l}\text { Positioning of spoon bowl } \\
\text { during food intake }\end{array}$ & 2 \\
\hline 3 & $\begin{array}{l}\text { Motion of the lips during food } \\
\text { intake }\end{array}$ & 2 \\
\hline 3 & Neck rotation & 3 \\
\hline 3 & $\begin{array}{l}\text { Occupancy of spoon bowl to } \\
\text { aperture of mouth }\end{array}$ & 2 \\
\hline
\end{tabular}

This typically developing child is in a stable upper body position, and ingesting food by closing the lips. The child is putting ! the spoon into the mouth at the middle of the lips.

Food intake behavior This child with PDD, rotating the neck to the right, is ingesting food by pulling the spoon out of the mouth because of poor strength of the lips. The position of the right upper limb is apart from the middle of the trunk.

Fig. 1 Examples of assessment when taking in food.

for the PDD children vs. the assessment for the controls; the second assessment for the PDD children vs. the assessment for the controls. The data were statistically analyzed using the Mann-Whitney U test, with SPSS ver. 19.0. Subsequently, correlations between the feeding assessments (first and second) and Enjoji Scale were 
Table 2 Criteria for Functional Examinations of Eating Behavior.

1. Positioning of spoon bowl during food intake

1) Passing across the front teeth

2) Contact with front teeth

3) Touch lip or food in spoon

2. Motion of the lips during food intake

1) Not working (capturing with the teeth)

2) Working slightly (food intake by spoon handling)

3) Food capturing with the lips

3. Neck rotation

1) Frequent

2) Occasional

3) Never

4. Occupancy of spoon bowl to aperture of mouth ${ }^{\mathrm{a}}$

1) Parallel

2) Less than 45 degrees

3) More than 45 degrees

Criteria for the functional examinations were composed of 3 categories, assigned scores of, 1, 2 or 3 points, respectively.

${ }^{a}$ Occupancies of spoon bowl were divided into 3 groups based the angulation on the horizontal plane between the long axis of the spoon and the aperture of the mouth.

calculated using Spearman's rank correlation test, again with SPSS.

This study was approved by the ethics committee of the School of Dentistry, Showa University (approval No. 2008-12).

\section{Results}

\section{Proportions of each score in the feeding assess- ment}

The proportions of each score in the feeding assessment for children with PDD (first and second assessments) and the controls are shown in Fig. 2.

As for "positioning of spoon bowl during food intake" in the PDD group, the values decreased from $73 \%$ to $58 \%$ for Score 1 (passing across the front teeth), and increased from $21 \%$ to $42 \%$ for Score 2 (contact with front teeth). Behavior of Score 3 (touching lip or food in spoon) was not observed. As for "motion of the lips during food intake," the values increased from $10 \%$ to $29 \%$ for Score 1 (not working), decreased from $80 \%$ to
$48 \%$ for Score 2 (working slightly), and increased from $10 \%$ to $23 \%$ for Score 3 (food capturing with the lips). As for "neck rotation," all responses were judged to be Score 2 (working slightly) for both the first and the second assessment. As for "occupancy of spoon bowl to aperture of mouth," the values decreased from $33 \%$ to $19 \%$ for Score 1(parallel), increased from 54\% to $56 \%$ for Score 2 (less than 45 degrees) and from $13 \%$ to $25 \%$ for Score 3 (more than 45 degrees).

In the control group, $90 \%$ of the responses to "positioning of spoon bowl during food intake" were judged to be Score 1 and the remaining $10 \%$ to be Score 2. As for "motion of the lips during food intake" and "neck rotation", all responses were judged to be Score 3. As for "occupancy of spoon bowl to aperture of mouth," $60 \%$ of responses were judged to be Score 2 and the remaining $40 \%$ to be Score 3 .

\section{Comparison between the feeding assessment datasets}

The results of the analysis are shown in Table 3.

Comparison between the first and second feeding assessments in the PDD group revealed a significant difference only in "occupancy of spoon bowl to aperture of mouth" $(\mathrm{p}<0.05)$. There were no significant differences in other items.

Comparison between the first assessment in the PDD group and the assessment in the control group revealed significant differences $(\mathrm{p}<0.01)$ in "motion of the lips during food intake," "neck rotation," and "occupancy of spoon bowl to aperture of mouth" but not in "positioning of spoon bowl during food intake."

Comparison between the second assessment in the PDD group and the assessment in the control group revealed significant differences in all items $(p<0.01)$ for "positioning of spoon bowl during food intake", "motion of the lips during food intake" and "neck rotation" as well as in "occupancy of spoon bowl to aperture of mouth" $(\mathrm{p}<0.05)$.

\section{Correlations between feeding assessment and Enjoji Scale}

The obtained correlation coefficients are shown in 
Positioning of spoon bowl during food intake

Motion of the lips during food intake

Neck rotation

Occupancy of spoon bowl to aperture of mouth
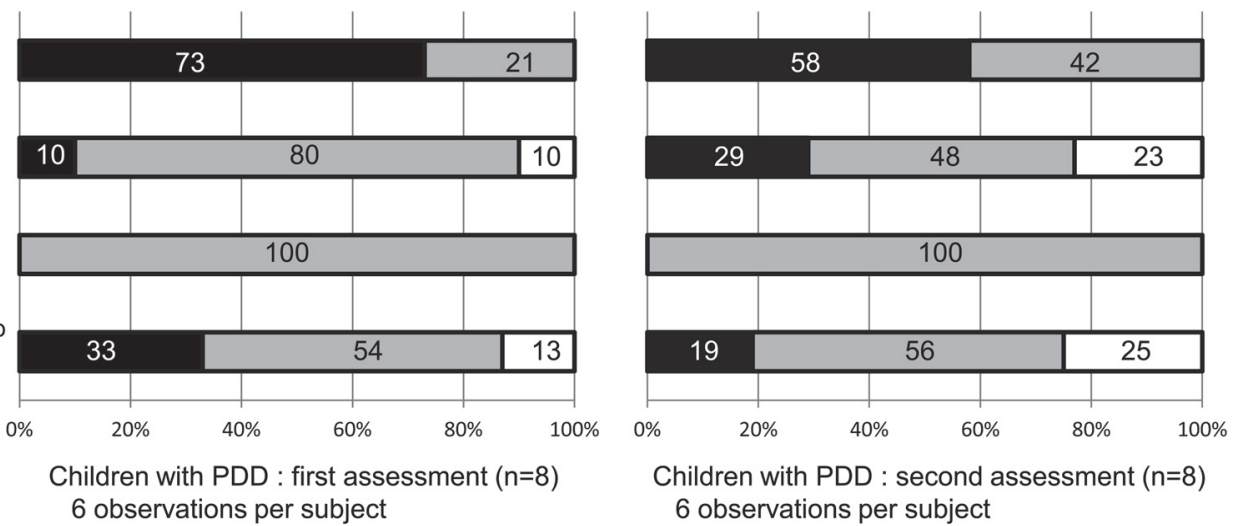

Positioning of spoon bowl during food intake

Motion of the lips during food intake

Neck rotation

Occupancy of spoon bowl to aperture of mouth
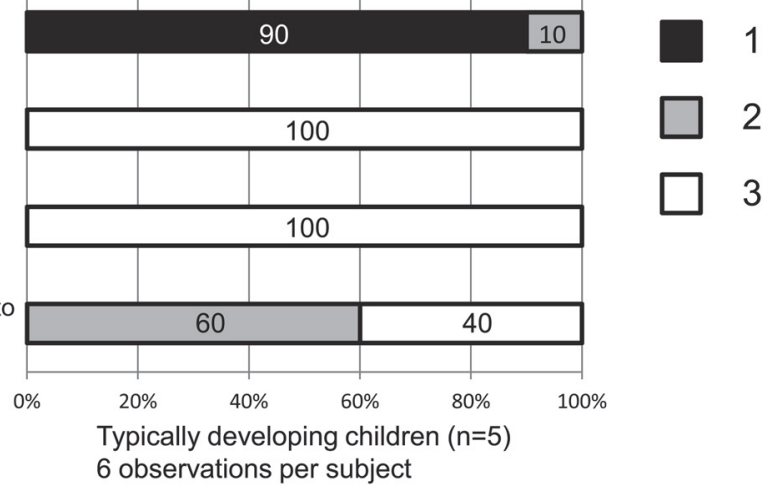

Fig. 2 Frequency of assessment items among total observations.

Table 3 Test of assessment items in children with PDD and typically developing children.

\begin{tabular}{lccc}
\hline & $\begin{array}{c}\text { Children with PDD } \\
\text { (first assessment) } \\
\text { vs. }\end{array}$ & $\begin{array}{c}\text { Children with PDD } \\
\text { (first assessment) } \\
\text { vs. }\end{array}$ & $\begin{array}{c}\text { Children with PDD } \\
\text { (second assessment) } \\
\text { Vs. }\end{array}$ \\
& $\begin{array}{c}\text { Children with PDD } \\
\text { (second assessment) }\end{array}$ & $\begin{array}{c}\text { Typically developing } \\
\text { children }\end{array}$ & $\begin{array}{c}\text { Typically developing } \\
\text { children }\end{array}$ \\
\hline Positioning of spoon bowl during food intake & n.s. & n.s. & $* *$ \\
Motion of the lips during food intake & n.s. & $* *$ & $* *$ \\
Neck rotation & n.s. & $* *$ & $* *$ \\
Occupancy of spoon bowl to aperture of mouth & $*$ & $* *$ \\
\hline
\end{tabular}

n.s. not significant Mann-Whitney $U \quad * \mathrm{p}<0.05 \quad * * \mathrm{p}<0.01$

Table 4.

In the first assessment, "positioning of spoon bowl during food intake" had significant negative correlations with all items of the Enjoji Scale ( $<<0.01$ for "physical movement," "hand movement," "basic daily habits," and "speaking"; p $<0.05$ for "age," "personal relations," and "understanding of language"), whereas "motion of the lips during food intake" and "occupancy of spoon bowl to aperture of mouth" showed no significant correlations with any items of the Enjoji Scale. Computing of the correlation coefficient was not possible for "neck rotation."

In the second assessment, "positioning of spoon bowl during food intake" had significant negative correlations with all items of the Enjoji Scale $(p<0.01$ for "physical movement,", "hand movement," "basic daily habits," "speaking," and "understanding of language"; $p<0.05$ for "age" and "personal relations"). "Motion of the lips during food intake" also had significant correlations with all items of the Enjoji Scale $(\mathrm{p}<0.01$ for "hand 
Table 4 Correlations between assessment items and each Enjoji Scale Item of the Infant Analytical Development Test. First Assessment

\begin{tabular}{|c|c|c|c|c|c|c|c|c|}
\hline & & Age & $\begin{array}{c}\text { Physical } \\
\text { movement }\end{array}$ & $\begin{array}{c}\text { Hand } \\
\text { movement }\end{array}$ & $\begin{array}{l}\text { Basic daily } \\
\text { habits }\end{array}$ & $\begin{array}{l}\text { Personal } \\
\text { relations }\end{array}$ & Speaking & $\begin{array}{c}\text { Understanding } \\
\text { of language }\end{array}$ \\
\hline \multirow{2}{*}{$\begin{array}{l}\text { Positioning of spoon bowl } \\
\text { during food intake }\end{array}$} & Correlation & -0.344 & -0.504 & -0.559 & -0.45 & -0.313 & -0.515 & -0.331 \\
\hline & coefficient & * & $* *$ & $* *$ & $* *$ & $*$ & $* *$ & $*$ \\
\hline \multirow{2}{*}{$\begin{array}{l}\text { Motion of the lips during } \\
\text { food intake }\end{array}$} & Correlation & 0.091 & -0.01 & 0.151 & 0.021 & 0.142 & 0.06 & 0.091 \\
\hline & coefficient & n.s. & n.s. & n.s. & n.s. & n.s. & n.s. & n.s. \\
\hline \multicolumn{2}{|l|}{ Neck rotation } & n.s. & n.s. & n.s. & n.s. & n.s. & n.s. & n.s. \\
\hline \multirow{2}{*}{$\begin{array}{l}\text { Occupancy of spoon bowl } \\
\text { to aperture of mouth }\end{array}$} & Correlation & 0.128 & 0.151 & 0.186 & 0.179 & 0.069 & 0.146 & 0.07 \\
\hline & coefficient & n.s. & n.s. & n.s. & n.s. & n.s. & n.s. & n.s. \\
\hline \multicolumn{9}{|l|}{ Second Assessment } \\
\hline \multirow{3}{*}{$\begin{array}{l}\text { Positioning of spoon bowl } \\
\text { during food intake }\end{array}$} & & Age & $\begin{array}{c}\text { Physical } \\
\text { movement }\end{array}$ & $\begin{array}{c}\text { Hand } \\
\text { movement }\end{array}$ & $\begin{array}{c}\text { Basic daily } \\
\text { habits }\end{array}$ & $\begin{array}{l}\text { Personal } \\
\text { relations }\end{array}$ & Speaking & $\begin{array}{c}\text { Understanding } \\
\text { of language }\end{array}$ \\
\hline & Correlation & -0.295 & -0.424 & -0.399 & -0.371 & -0.366 & -0.387 & -0.510 \\
\hline & coefficient & $*$ & $* *$ & $* *$ & $* *$ & $*$ & $* *$ & $* *$ \\
\hline \multirow{2}{*}{$\begin{array}{l}\text { Motion of the lips during } \\
\text { food intake }\end{array}$} & Correlation & 0.345 & 0.289 & 0.417 & 0.561 & 0.539 & 0.712 & 0.573 \\
\hline & coefficient & * & $*$ & $* *$ & $* *$ & $* *$ & $* *$ & $* *$ \\
\hline \multicolumn{2}{|l|}{ Neck rotation } & n.s. & n.s. & n.s. & n.s. & n.s. & n.s. & n.s. \\
\hline \multirow{2}{*}{\multicolumn{2}{|c|}{$\begin{array}{l}\text { Occupancy of spoon bowl } \\
\text { to aperture of mouth }\end{array}$}} & 0.281 & -0.188 & 0.076 & 0.103 & 0.123 & 0.058 & 0.060 \\
\hline & & n.s. & n.s. & n.s. & n.s. & n.s. & n.s. & n.s. \\
\hline
\end{tabular}

n.s. not significant $\operatorname{Spearman} \rho * \mathrm{P}<0.05 * * \mathrm{P}<0.01$

movement," "basic daily habits," "personal relations," "speaking," and "understanding of language"; $p<0.05$ for "age" and "physical movement," whereas "occupancy of spoon bowl to aperture of mouth" showed no significant correlations with any item of the Enjoji Scale. Computing of the correlation coefficient was not possible for "neck rotation."

\section{Discussion}

\section{Proportions of each score in the feeding assess- ment}

\section{1) Food intake function}

Children with PDD showed a distinctly different pattern from that of the controls in "motion of the lips during food intake." Whereas all responses of the controls were judged to be Score 3 (food capturing with the lips), those of children with PDD showed a variety of responses (i.e., Score 1, 2, or 3). In the analysis of change from the first to the second assessment, decreased values were observed for Score 2, whereas increased values were found in Scores 1 and 3. Chigira et $\mathrm{al}^{2)}$ reported that normally developing children became able to capture food with the lips around 5 to 6 months of age. Morris and Klein ${ }^{19)}$ reported that normally developing children begin capturing food with the lips in spoon feeding around 7 months of the age, and capturing food with the teeth around age 15 months. They commented that lipcapturing is followed by teeth-capturing. The present study revealed that children with PDD showed lesser lip motion during food intake. We consider this to be one of the characteristics of children with PDD in spoon feeding. They tend to capture food with the teeth rather than the lips. This tendency may be related to the sensitivity of their front teeth. ${ }^{20)}$ On the contrary, their lesser lip motion may result from sensitivity of the lips. ${ }^{21)}$ It has been reported that children with PDD have a variety of sensory disorders. $^{22)}$ Therefore, forced use of the lips may not be an appropriate treatment. On the other hand, the sensory abnormality was reportedly alleviated by intervention using a kind of sensory integrative approach. ${ }^{23)}$ Sensory assessment and treatment were therefore recommended before instructing children to use the lips during food intake.

Nomoto et $\mathrm{al}^{7)}$ investigated feeding disorders of intellectually impaired children using the same items as in the present study. They reported that the score 
became 3 in 8 of 10 subjects 1 year after receiving therapeutic intervention for food intake skills, incision of the front teeth, and so on. In the present study, no therapeutic interventions were performed. As previously noted, sensory impairment was considered to be one of the reasons for failing to capture food with the lips. Considering the marked improvement observed in Nomoto et al's subjects, the lesser improvement in our subjects might be partly attributable to the absence of therapeutic intervention. Further evaluation of the effectiveness of therapeutic intervention for food intake skills and incision of the front teeth for children with PDD is awaited.

As for "positioning of spoon bowl during food intake," most of the responses were judged to be Score 1 (passing across the front teeth) for both groups. It has been reported that children with immature food capturing skills tend to put the spoon deep into the oral cavity when the bowl part of the spoon is smaller than the width of the lips. ${ }^{6)}$ In the present study, the participants used spoons which they had been using at the center. It was assumed that the bowl part of the spoon was small. Therefore, the aforementioned result might be partly attributable to the size of the spoon bowl. As an alternative explanation, the children had developed awareness of eating such that they tried to put the spoon deep into the oral cavity in order to compensate for immature hand and mouth functions.

\section{2) Hand-mouth coordination}

If a child has a restricted range of shoulder joint motion, he or she may compensate by rotating the neck or putting the spoon into the mouth from the lateral side. Thus, "neck rotation" and "occupancy of spoon bowl to aperture of mouth" are considered to be related. The present results are consistent with this idea.

Comparison between the first and second assessments for children with PDD revealed no change in "neck rotation," but there was an improvement in "occupancy of spoon bowl to aperture of mouth" (the proportions of Scores 2 and 3 increased). We speculate that children with PDD might have been compensating for restricted shoulder joint motion by neck rotation.

In the control group, all observations of "neck rotation" were judged to be Score 3 whereas "occupancy of spoon bowl to aperture of mouth" was judged to be Score 2 or 3 (more than half of responses were Score 2). The controls were considered to be compensating for restricted range of shoulder joint motion by the putting spoon into the mouth from the lateral side. Considering that ages of the controls started at 32 months, neck rotation as a compensating behavior may not appear earlier than this.

In the present age-matched study, the children who had Score 2 for "neck rotation" and Score 3 for "occupancy of spoon bowl to aperture of mouth" were fewer in number than those with PDD, as compared with the control group. This allows us to hypothesize that children with PDD might have restricted range of shoulder joint motion. It has been reported that children with PDD are clumsy, i.e. have poor motor skills. ${ }^{24)}$ We consider restricted range of shoulder joint motion to possibly be one of the developmental delay of motor-skills in children with PDD.

\section{Comparison between feeding assessment datasets}

Comparison between the first and second assessments for children with PDD revealed a significant difference only in "occupancy of spoon bowl to aperture of mouth" $(\mathrm{p}<0.05)$, suggesting that children with PDD showed a certain degree of development in the range of shoulder joint motion during the study period.

Comparison between the children with PDD and the control group revealed significant differences $(\mathrm{p}<0.01)$ for both the first and second assessment in "motion of the lips during food intake." We consider evaluating the role of the lips (including evaluation of sensory impairment of the lips, as previously described) to be important when assessing food intake behavior of children with PDD. There were also significant differences $(p<0.01)$ for both the first and second assessment in "neck rotation." As previously noted, the children with PDD showed a certain degree of neck rotation even in the second assessment, suggesting that neck rotation is also one 
of the important items in the assessment of food intake behavior in children with PDD.

Feeding function has a major effect on life maintenance, vitality, and growth and development. Feedingrelated behavior problems in children with PDD have been a concern for parents and specialists, and a significant research effort was made in this area. ${ }^{25)}$ The Parental Concerns Questionnaire (a 13-item questionnaire for parents of children with autism spectrum disorders) includes an item on "eating habits". ${ }^{26)}$ The Brief Autism Mealtime Behavior Inventory (BAMBI) is a questionnaire focusing on feeding behavior. ${ }^{27)}$ Children with autism display a variety of inappropriate behaviors such as food selectivity, distaste for new foods, pica, selectivity for cooking methods, holding food in the mouth, spitting food, throwing food, and eating place selectivity. Many investigators have focused on food selectivity. ${ }^{28)}$ While there is significant difference in food intake behavior between children with PDD and controls, we advocate that evaluation of food intake behavior be included in the screening tests. The effects of sensory impairment and motor programming disorders on eating behavior in children with autism have been noted. ${ }^{29)}$ The lesser motion of lips during food intake in children with PDD may partly result from hypersensitivity of the lips. The developmental delay in hand-mouth coordination may partly result from a motor programming disorder.

3. Correlations between feeding assessment and Enjoji Scale

Among the screening tests for infants with suspected developmental delay, the Denver Developmental Screening Test II is widely used in pediatrics in western countries. ${ }^{30)}$ In Japan, the Enjoji Scale has been widely used in research and clinical practice. ${ }^{31)}$ There is an opinion that appropriate timing of intervention for feeding function disorders in children with developmental delay should be determined based on developmental rather than chronological age. ${ }^{32)}$ Development of feeding function has a strong relationship with developmental age in children. Although there are many developmental screening tests for children with PDD, ${ }^{33)}$ the Enjoji Scale was employed in the present study. This scale had been used in the children's disability center attended by our participants.

"Neck rotation" and "occupancy of spoon bowl to aperture of mouth" had no significant correlations with any Enjoji Scale items on the first or the second assessment. These 2 items were considered to be influenced by motor development, i.e., range of shoulder joint motion development.

"Positioning of spoon bowl during food intake" had significant correlations with all Enjoji Scale items for both the first and second assessment $(\mathrm{p}<0.05$ or 0.01 ). The Enjoji Scale items showing significant correlations $(p<0.01)$ for both the first and second assessment were "physical movement," "hand movement," "basic daily habits," and "speaking." These items are related to motor-skills development. The items showing significant correlations $(\mathrm{p}<0.05)$ for both the first and second assessment were "age" and "personal relations." "Understanding of language" showed a significant correlation for the first $(\mathrm{p}<0.05)$ and for the second assessment $(\mathrm{p}<0.01)$. The "positioning of spoon bowl during food intake" correlated negatively with "physical movement," "hand movement," "basic daily habits," "speaking," and "understanding of language," suggesting that feeding behaviors such as putting spoon deep into the oral cavity or capturing food with the front teeth cannot be explained by developmental delay in motor function. As mentioned above, awareness of feeding might be related to these behaviors.

"Motion of the lips during food intake" had no significant correlations with any Enjoji Scale items for the first assessment, but showed significant correlations with all items for the second assessment. Significant correlations $(p<0.01)$ were found in "hand movement," "basic daily habits," "personal relations," "speaking" and "understanding of language", and in "age" and "physical movement" $(p<0.05)$. It was suggested that therapeutic education for children during the about 1 -year period might have influenced these results.

Preschool children have great plasticity in the brain. 
During this developmental period, therapeutic education by teachers, therapists or parents can be highly effective. Recently, the efficacies of various intervention methods have been evaluated. ${ }^{34)}$ As shown in the present study, food intake functions, especially lip function, can easily be evaluated in medical settings, schools or the home, and the effects of intervention are easily understandable. In conclusion, among the wide range of behavioral characteristics, lip function is considered to be an important index for assessing feeding behavior and language development in children with PDD.

\section{References}

1) Leopold NA, Kagel MC: Dysphagia-Ingestion or deglutition? : A proposed paradigm. Dysphasia, 12: 202-206, 1997

2) Chigira A, Omoto K, Mukai Y, Kaneko Y: Lip closing pressure in disabled children: A comparison with normal children. Dysphagia, 9: 193-198, 1994

3) Leopold NA, Daniels SK: Supranuclear control of swallowing. Dysphagia, 25: 250-257, 2010

4) Kaneko Y, Mukai Y, Omoto K: Disorders in Eating Function: Its Concept and Application to the Rehabilitation Program, Tokyo, 1987, Ishiyaku Publishers, pp.22-32 (in Japanese)

5) Mukai Y: The treatment for dysphagia. Dentistry for the Handicapped, 16:145-155, 1995 ( in Japanese)

6) Tamura F, Chigira A, Ishii H, Nishikata H, Mukai Y: Assessment of the development of head coordination when taking food into the oral cavity. Int J Orofacial Myology, 26: 33-43, 2000

7) Nomoto T, Mega J, Mukai Y: A study on eating disorder of intellectually impaired children-Coordination between movement of hand and mouth at food intake- . Dentistry in Japan, 37: 144-149, 2001

8) American Psychiatric Association: Diagnostic and statistical manual of mental disorders, fourth edition, text revision. Washington, 2000, American Psychiatric Association

9) Casanova MF, Buxhoeveden DP, Switala AE, Roy E: Minicolumnar pathology in autism. Neurology, 58: 428-432, 2002

10) Baranek GT, David FJ, Poe MD, Stone WL, Watson LR: Sensory experiences questionnire: discriminating sensory features in young children with autism, developmental delays and typical development. J Child Psychology and Psychiatry, 47: 591-601, 2006

11) Manjiviona J, Prior M: Comparison of Asperger syndrome and high-functioning autistic children on a test of motor impairment. J Autism Dev Disord, 25: 23-39, 1995

12) Schreck KA, Williams K: Food preference and factors influencing food selectivity for children with autism spectrum disorders. Res Dev Disabil, 27: 353-363, 2006

13) Williams PG, Dalrymple N, Neal J: Eating habits of children with autism. Pediatr Nurs, 26: 259-264, 2000

14) Keen DV: Childhood autism, feeding problems and failure to thrive in early infancy Seven case studies. Eur Child Adolesc Psychiatry, 17: 209-216, 2008

15) Gentry JA, Luiselli JK: Treating a child's selective eating through parent implemented feeding intervention in the home setting. J Dev Phys Disabil, 20: 63-70, 2008

16) Ahearn WH, Castine T, Nault K, Green G: An assessment of food acceptance in children with autism or pervasive developmental disorder-not otherwise specified. J Autism Dev Disord, 31: 505-511, 2001

17) Seiverling L, Williams K, Sturmey P: Assessment of feeding problems in children with autism spectrum disorders. J Dev Phys Disabil, 22: 401-413, 2010

18) Enjoji M, Aiya N: Enjoji Scales of Infant Analytical Development Test. Tokyo, 1980, Keioutusin (in Japanese)

19) Morris SE, Klein MD: Pre-feeding skills. A Comprehensive Resource For Mealtime Development 2nd ed. Austin, 2000, PRO-ED Inc., pp. 81-82

20) Yagi S, Fukuyama E, Soma K: Involvement of sensory input from anterior teeth in deglutitive tongue function. Dysphagia, 23: 221-229, 2008

21) Capra NF: Mechanisms of oral sensaition. Dysphagia, 10: 235-247, 1995

22) Chen YH, Rodgers J, McConachie H: Restricted and repetitive behaviours, sensory processing and cognitive style in children with autism spectrum disorders. J Autism Dev Disord, 39: 635-642, 2009

23) Reilly JT, Amaral SC, Zebrowski PP: Addressing feeding disorders in children on the autism spectrum in school-based settings: physiological and behavioral issues. Language, Speech, and Hearing Services in Schools, 39: 261-272, 2008

24) Waelvelde H, Oostra A, Dewitte G, Broeck CVD: Stability of motor problems in young children with or at risk of autism spectrum disorders, ADHD, and or developmental coordination disorder. Dev Med Child Neurol, 52: e174-e178, 2010

25) Kodak T, Piazza CC: Assessment and behavioral treatment of feeding and sleeping disorders in children with autism aspectrum disorders. Child Adolesc Psychiatr Clin N Am, 17: 887905, 2008

26) McGrew S, Malow BA, Henderson L, Wang L, Song Y, Stone WL: Developmental and behavioral questionnaire for autism spectrum disorders. Pediatr Neurol, 37: 108-116, 2007

27) Lukens CT, Linscheid TR: Development and validation of an inventory to assess mealtime behavior problems in children with autism. J Autism Dev Disord, 38: 342-352, 2008

28) Provost B, Crowe TK, Osbourn PL, McClain C, Skipper B: Mealtime behaviors of preschool children: comparison of children with autism spectrum disorder and children with typical development. Phys Occup Ther Pediatr, 30: 220-233, 2010

29) Morris SE, Klein MD : Pre-Feeding Skills. A Comprehensive Resource For Mealtime Development 2nd ed, Austin, PROED Inc., pp. 670-671, 2000

30) Barratt MS, Moyer VA: Pediatric resident and faculty knowl- 
edge of the Denver II. Arch Pediatr Adolesc Med, 154: 411413, 2000

31) Ohba S, Era S: Developmental descriptions in the literature relating to children with severe/profound and multiple disabilities. Bull Joetsu Univ Educ, 21: 661-673, 2002 (in Japanese)

32) Arvedson JC: Oral-motor and feeding assessment. In Arvedson JC, Brodsky L (eds): Pediatric Swallowing and
Feeding. Assessment and Management. San Diego, 1993, Singular Publishing Group, Inc., pp. 252-253

33) Rydz D, Shevell MI, Majnemer A, Oskoui M: Developmental Screening. J Child Neurology, 20: 4-21, 2005

34) Boyd BA, Odom SL, Humphreys B, Sam AM: Infants and toddlers with autism spectrum disorder: early identification and early intervention. J Early Intervention, 32: 75-98, 2010 